\title{
Response of Landscape and Ecological Characteristics to the Optimal Rainwater Harvesting Dual-Element Mulch Covered Soil Model in Beijing
}

\author{
Caiyuan Wang ${ }^{1,2}$, Peiling Yang ${ }^{1, *}$, Yunkai Li ${ }^{1}$, Zhongshan Yang ${ }^{2}$, Shumei Ren ${ }^{1}$, Min Zang ${ }^{2}$, \\ Yajuan Wang ${ }^{2}$ and Xin Zhang ${ }^{2}$ \\ 1 College of Water Resources and Civil Engineering, China Agricultural University, Beijing 100083, China; \\ wangcaiyuan555@163.com (C.W.); liyunkai@1126.com (Y.L.); renshumei@126.com (S.R.) \\ 2 Beijing Hydrological Center, Beijing 100089, China; gsh5566449868@163.com (Z.Y.); \\ whzm79@163.com (M.Z.); 17640133045@163.com (Y.W.); zhouzh@mwr.gov.cn (X.Z.) \\ * Correspondence: yangpeiling@126.com
}

Received: 26 February 2019; Accepted: 12 March 2019; Published: 29 March 2019

\begin{abstract}
The implementation of energy conservation and emissions reduction in Beijing prompted yearly increases in the area of urban green space, leading to direct increases in urban water consumption. This aggravated an already tense situation of water shortage. Considering the low irrigation water utilization effectives of the urban green space system, the typical urban greening shrub (Ligustrum vicaryi) was selected as the research object of this study. In a pot experiment, three mulch materials were selected: gravel $(\mathrm{CH} 1)$, pine needles + gravel $(\mathrm{CH} 2)$, and bark + gravel $(\mathrm{CH} 3)$. These materials were set to a uniform thickness of $3 \mathrm{~cm}$, and soil water was maintained between $75 \%$ and $85 \%$ of the field capacity. Using the analytic hierarchy process and fuzzy mathematics model, the physiological and ecological response characteristics of Ligustrum vicaryi were investigated under different combinations of mulch material. The results for various processing, regarding plant growth, showed $\mathrm{CH} 3>\mathrm{CH} 2>\mathrm{CH} 1>\mathrm{CK}$ (Control Check). The leaf area, total leaf area, and leaf area index of $\mathrm{CH} 3$ were, respectively, $21.4 \%, 21.9 \%$, and $62.5 \%$ larger than those of the control check (CK). Regarding physiological characteristics, photosynthetic rate, evaporation rate, stomatal conductance, and water use efficiency of $\mathrm{CH} 3$ were better than for the other treatments. Regarding ecological services, carbon fixation, oxygen release, cooling, and quantity of humidification of $\mathrm{CH} 3$ were optimal. Considered comprehensively for the landscape function, physical characteristics, and ecological services of Ligustrum vicaryi, the preliminary thought is that bark and gravel dual-element mulch, with a layer thickness of $3 \mathrm{~cm}$, was the optimal soil cover treatment for the typical city greening shrub Ligustrum vicaryi. Using the analytic hierarchy process (AHP) and the fuzzy mathematical model for the evaluation of the effects of different soil cover treatments on the landscape function, ecological service function, and physiological characteristics of Ligustrum vicaryi was reliable and feasible. The model evaluation results match the actual ones.
\end{abstract}

Keywords: Ligustrum vicaryi; landscape function; ecological service function; mulch conservation

\section{Introduction}

Green plants can beautify the environment and purify air, and can also fix greenhouse gases, especially $\mathrm{CO}_{2}$ gas in the air, then release $\mathrm{O}_{2}$ through photosynthesis [1,2]. Green plants could lower ambient temperature in the surrounding environment and increase air humidity by leaf transpiration water loss, which provides balance between the urban landscape and ecological environment [3-5]. Global activities for energy conservation and emissions reduction have promoted rapid development of urban green space area and led to increasing water consumption, which has accelerated the already 
tense situation of water resource shortage [6,7]. Moreover, the water use efficiency has been low, causing the waste of water resources during the processes of green space construction and irrigation management. The proper soil cover could conserve soil moisture, reduce water loss from soil surface evaporation, stabilize the soil temperature, and increase the efficiency of plants water use $[8,9]$. At the same time, the soil cover also has played a role in the beautification of urban landscape.

The conditions provided by the current natural climate in Beijing are poor. Limited rainfall and active evaporation have led to a soil water deficit. Research on soil cover conservation patterns have previously mainly concentrated on crops. However, research is not sufficiently in-depth or systematic to inform soil conservation measures based on ground cover for horticultural plants. Cook et al. studied the influence of rainfall interception, soil physical properties, and temperature under different mulch covers [10]. Li et al. studied the influence of evapotranspiration and water use efficiency of cabbage with different degrees of soil coverage in a pot experiment. The results show that the water use efficiency of cabbage increased with increasing degree of soil coverage [11]. Wang et al. studied on the influence of crop water use efficiency and crop yield for different kinds of cover mulch, and suggested mulching and supplementary irrigation to improve rainwater availability for high sustainable crop yield [12]. Ma et al. studied the effect of gravel mulch on sea buckthorn growth, and thought that the gravel mulch could promote sea buckthorn survival and growth [13]. Liu et al. studied the effect of soil water dynamics and water use efficiency of corn in relation to different soil coverage measures [14]. Soil conservation research on soil cover for greening plants was the main topic, but references for crop research had the main goals of crop yield and fruit quality. Because the greening plants are different from crops, results about their yield and quality did not help with the ultimate goal of this research: The landscape and ecological service functions of greening plants. In order to resolve this situation, we must change the direction of research toward the soil conservation pattern of soil cover of greening plants, to seek the optimal covered soil conservation mode, considering comprehensive landscape and ecological service functions. The ultimate purpose is to provide a theoretical basis for green space construction and administration.

In this article, we report the results of our study on the effect of Ligustrum vicaryi growth, physiological characteristics, landscape functions, and ecological service functions in a pot experiment involving different soil conservation modes. Based on these parameters, the applied analytic hierarchy process (AHP) and a fuzzy mathematics model were used to provide a comprehensive evaluation. The optimal covered soil conservation mode was determined based on comprehensive consideration of plant physiology, landscape function, and ecological service function. This approach has important significance for the development of a low-carbon economy, for low-carbon urban construction, and for alleviating the water shortage in Beijing.

\section{Materials and Methods}

\subsection{Experimental Materials}

The shrub Ligustrum vicaryi was selected for this study because it is a typical shrub often used in Beijing greening projects. The experiment was conducted at the College of Water Conservancy and Civil Engineering, China Agricultural University ( $39^{\circ} 569$ N, $116^{\circ} 17$ E) during 2011 to 2012. The climate at the experimental site is "warm sub-humid continental monsoon," with an average temperature of $12.8^{\circ} \mathrm{C}$, annual effective accumulative temperature of $4500^{\circ} \mathrm{C}$, frost-free period of 189 days, annual rainfall of 450-650 mm, and annual evaporation of $1835.8 \mathrm{~mm}$. Those pots were $26.5 \mathrm{~cm}$ in height and $35 \mathrm{~cm}$ in diameter. Three small holes were made at the bottom of the pots in order to maintain the soil permeability and to prevent water accumulating on the pot floor. The soil samples were collected from the experimental field of the China Agriculture University. The soil texture was sandy soil. The total nitrogen, total phosphorus, and total potassium were, respectively, $2.4,0.6$, and $11.8 \mathrm{~g} / \mathrm{kg}$ in this soil. Its available nitrogen, available phosphorus, available potassium, and organic matter were, respectively, $0.6,0.8,3.0$, and $18.1 \mathrm{~g} / \mathrm{kg}$. The cationic exchange capacity was $9.87 \mathrm{~mol} / \mathrm{kg}$, and $\mathrm{pH}$ 
was 7.49. After air drying and sieving through a $2 \mathrm{~mm}$ mesh, the soil was packed to a bulk density of $1.35 \mathrm{~g} / \mathrm{cm}^{3}$, and left $5 \mathrm{~cm}$ below the pot top brim to avoid water overflow. The mass of the soil in each pot was $15.47 \mathrm{~kg}$. For better survival rate of Ligustrum vicaryi, all seedlings were fully irrigated within a month after transplanting. During the experiment, the soil moisture condition was controlled by the weight method.

\subsection{Experimental Design}

For this experiment, three treatments were prepared, based on ground cover materials: gravel (CH1); pine needle and gravel mulch (CH2); and tree bark and gravel mulch (CH3). For the control check $(\mathrm{CK})$, no mulch was used. Each treatment was repeated six times. The mulch materials were used to cover the soil uniformly to a thickness of $3 \mathrm{~cm}$ [9]. Soil water was controlled to remain between $75 \%$ and $85 \%$ of field capacity (FC). During the experiment, an electronic balance was used to monitor soil water regularly, according to change in the ambient temperature. For the sake of accuracy, water was added using beakers with volume of 100 and $400 \mathrm{~mL}$. A small tray was put under each pot, to catch the water leaking from the gap between soil and the pot. Then, the water seepage was re-poured into the pots slowly to ensure appropriate soil moisture for each treatment.

\subsection{Characterization of Landscape Function}

In considering urban horticultural plants, the landscape function was particularly important. The landscape function of greening plants is mainly embodied in the size of leaves, sparsity or abundance of leaves, and the color of the leaves. For this part of the experiment, three parameters were set: leaf area (LA), total leaf area (TLA), and the leaf area index (LAI).

LA reflected the size of leaf, and TLA was calculated as in Equation (1).

$$
\mathrm{S}_{1}=\mathrm{S}_{2} \times \mathrm{W}_{1} / \mathrm{W}_{2}
$$

where $S_{1}$ is the total leaf area, $\mathrm{cm}^{2} ; S_{2}$ is the leaf area scanned, $\mathrm{cm}^{2}$; these scanned leaves were randomly collected from top to the bottom around the whole tree, and then were pasted on the grid paper to scan. The one leaf area was calculated by the AutoCAD, and the leaf area scanned were calculated according to the relationship between the leaf area and leaf weight. $W_{1}$ is the total fresh weight of the leaves, $g$, and these leaves were from the whole tree. $W_{2}$ is the fresh weight of the leaves scanned in grams. These scanned leaves were randomly collected from top to the bottom around the whole tree, and then were weighted.

LAI reflected the degree of sparsity of leaves, and was calculated as in Equation (2):

$$
\mathrm{LAI}=\mathrm{S}_{1} / \pi \mathrm{r}^{2}
$$

where LAI is the leaf area index; $\mathrm{S}_{1}$ is the total leaf area, $\mathrm{cm}^{2} ; \mathrm{r}$ is the average canopy radius, $\mathrm{cm}$.

In this paper, leaf color is expressed as chlorophyll content. For evergreen shrub species, the higher chlorophyll content, the better the landscape function.

\subsection{Characterization of Ecosystem Service Function}

\subsubsection{Fixing Carbon and Releasing Oxygen}

The assimilation of plants enclosed the area of net photosynthesis, and the horizontal axis of time in the curve of diurnal variation of plant photosynthesis. The photosynthesis rate was measured by the photosynthetic apparatus CL-340. The measurement was performed every two hours from $8 \mathrm{AM}$ to $6 \mathrm{PM}$ on the typical sunny day. Six leaves with good growth condition were selected from the 6 different locations in the top layer, middle layer, and bottom layer of the tree. 
On this basis, we assumed that the net photosynthesis was Pn, and the formula for calculating the net photosynthesis was as follows [15-17]:

$$
\mathrm{P}_{\mathrm{n}}=\sum_{i=1}^{j}\left[\left(P_{i+1}+P_{i}\right) \div 2 \times\left(t_{i+1}-t_{i}\right) \times 3600 \div 1000\right]
$$

where $P_{n}$ is the total assimilation in the sampling day $\left(\mathrm{mmol} \cdot \mathrm{m}^{-2} \cdot \mathrm{d}^{-1}\right) ; P_{i}$ is the instantaneous photosynthetic of the measured point; $P_{i+1}$ is the instantaneous photosynthetic of the next measured point $\left(\mu \mathrm{mol} \cdot \mathrm{m}^{-2} \cdot \mathrm{s}^{-1}\right) ; t_{i}$ is the instantaneous time of the measured point; $t_{i+1}$ is the instantaneous time of the next measured point, $h$; $j$ is the times of measuring; 3600 is $3600 \mathrm{~s} / \mathrm{h}$; and 1000 is $1000 \mu \mathrm{mol}$.

The total assimilation was converted to the amount of $\mathrm{CO}_{2}$ fixed:

$$
\mathrm{W}_{\mathrm{CO} 2}=\mathrm{P}_{\mathrm{n}} \cdot 44 / 1000
$$

where 44 is molar mass of $\mathrm{CO}_{2}\left(\mathrm{~g} \cdot \mathrm{mol}^{-1}\right) ; \mathrm{W}_{\mathrm{CO} 2}$ is the $\mathrm{CO}_{2}$ fixed per unit area of leaf $\left(\mathrm{g} \cdot \mathrm{m}^{-2} \cdot \mathrm{d}^{-1}\right)$. According to the reaction equation of photosynthesis:

$$
\mathrm{CO}_{2}+4 \mathrm{H}_{2} \mathrm{O} \rightarrow \mathrm{CH}_{2} \mathrm{O}+3 \mathrm{H}_{2} \mathrm{O}+\mathrm{O}_{2}
$$

The rate of oxygen release by trees is:

$$
\mathrm{W}_{\mathrm{O} 2}=P \cdot 32 / 1000
$$

and the unit is $\mathrm{g} \cdot \mathrm{m}^{-2} \cdot \mathrm{d}^{-1}$.

\subsubsection{Cooling and Humidification}

Cooling and humidification are based on the transpiration rate. The transpiration rate was measured by the photosynthetic apparatus CL-340. The measurement was performed every two hours from $8 \mathrm{AM}$ to $6 \mathrm{PM}$ on the typical sunny day. Six leaves with good growth condition were selected from the 6 different locations in the top layer, middle layer, and bottom layer of the tree, and was calculated using the formula [15-17]:

$$
\operatorname{Tr}=\sum_{i=1}^{j}\left[\left(e_{i+1}+e_{i}\right) \div 2 \times\left(t_{i+1}-t_{i}\right) \times 3600 \div 1000\right]
$$

where $\operatorname{Tr}$ is the total transpiration on the test day $\left(\mathrm{mmol} \cdot \mathrm{m}^{-2} \cdot \mathrm{s}^{-1}\right) ; e_{i}$ is the instantaneous rate of transpiration of the initial point measured; $e_{i+1}$ is the instantaneous rate of transpiration of the next point measured $\left(\mu \mathrm{mol} \cdot \mathrm{m}^{-2} \cdot \mathrm{s}^{-1}\right) ; t_{i}$ is the instantaneous time of the initial point measured; $t_{i+1}$ is the instantaneous time of the next measured point $(\mathrm{h})$; and $j$ is the period of measurement.

$$
W_{H 2 O}=\operatorname{Tr} \times 18
$$

where 18 is the molar mass of $\mathrm{H}_{2} \mathrm{O}$.

We assumed that the heat absorbed by Ligustrum vicaryi per square meter of leaves in a day was $Q$, due to transpiration of water; then

$$
Q=W_{H 2 O} \times L
$$

where $Q$ is the units of heat absorbed every day per leaf area, $\mathrm{kJ} /\left(\mathrm{m}^{2} \cdot \mathrm{d}\right)$; and $L$ is coefficient of evaporation heat consumption ( $L=2495-2.38 \times t, t$ is the temperature of measured day). 


\subsection{The Fuzzy Mathematical Model}

The comprehensive evaluation of the fuzzy mathematical model is to make a general evaluation of the things or objects that are restricted by many factors. Since the evaluation of things from many aspects is inevitably fuzzy and subjective, the comprehensive evaluation using the fuzzy mathematical method will make the results as objective as possible so as to achieve better practical results [18].

\subsubsection{The Determination of Weighting}

The analytic hierarchy process (AHP) was used to determine the weighting of each index of the comprehensive evaluation target. This method created a joint index by comparing two indexes. According to index $C_{i}$ and $C_{j}$ the contribution to (or influence on) the target gives a relative weight $a_{i j}(i$, $j=1,2 \ldots n$ ) between them. If the influence of $C_{i}$ and $C_{j}$ on the target is the same, take $a_{i j}=1$. If the effect of $C_{i}$ is slightly larger than the effect of $C_{j}$, take $a_{i j}=3$. If the effect of $C_{i}$ is larger than the effect of $C_{j}$, take $a_{i j}=5$. If the effect of $C_{i}$ is obviously larger than the effect of $C_{j}$, take $a_{i j}=7$. If the effect of $C_{i}$ is absolutely larger than the effect of $C_{j}$, take $a_{i j}=9$. If the effect is between two of the adjacent levels above, take the value between their corresponding levels. The ratio of $C_{j}$ to $C_{i}$ is $a_{j i}=1 / a_{i j}$. Construct judgment matrix $\mathrm{A}=\left(\mathrm{a}_{\mathrm{ij}}\right)$ based on the above principles, and the consistency check. The consistency check index (C.I.) is given by $(\lambda \max -n) /(n-1)$; where $n$ is index number and $\lambda \max$ is the largest eigenvalue of matrix A. Calculate the consistency ratio (C.R. = C.I./R.I.) using the random consistency index (R.I. in Table 1). When C.R. $<0.1$, and the consistency of matrix A is considered satisfactory, these show that the maximum eigenvalue $(\lambda \max )$, corresponding to the eigenvectors $W=\left(w_{1}, w_{2}, \Lambda, w_{n}\right)$, indicate that the target weight of the index $C_{1}, C_{2}, C_{3} \ldots C_{n}$ is acceptable. When C.R. $\geq 0.1$ is unacceptable, judgement matrix A will need to be corrected; so recalculate the consistency ratio C.R. until C.R. $<0.1$.

Table 1. The random consistency index (R.I.)

\begin{tabular}{ccccccccccc}
\hline $\boldsymbol{n}$ & $\mathbf{1}$ & $\mathbf{2}$ & $\mathbf{3}$ & $\mathbf{4}$ & $\mathbf{5}$ & $\mathbf{6}$ & $\mathbf{7}$ & $\mathbf{8}$ & $\mathbf{9}$ & $\mathbf{1 0}$ \\
\hline R.I. & 0 & 0 & 0.6 & 0.9 & 1.12 & 1.2 & 1.3 & 1.4 & 1.45 & 1.49 \\
\hline
\end{tabular}

\subsubsection{Establishment of Subordinate Function and Determination of Comprehensive Evaluation Set}

According to the division of the evaluation set using the fuzzy mathematical method, establish index data corresponding to its membership function.

(1) If bigger indicators would be better, use the upper limited linear membership function, $\operatorname{Uij}(x i)=$

$$
\left\{\begin{array}{c}
0 x_{i}<\min x_{i} \\
\left(x_{i}-\min x_{i}\right) /\left(\max x_{i}-\min x_{i}\right) \min x_{i}<x_{i}<\max x_{i} \\
1 x_{i}>\max x_{i}
\end{array}\right.
$$

(2) If smaller indicators would be better, use the lower limited linear membership function, $U i j(x i)=$

$$
\left\{\begin{array}{c}
1 x_{i}<\min x_{i} \\
\left(x_{i}-\max x_{i}\right) /\left(\min x_{i}-\max x_{i}\right) \min x_{i}<x_{i}<\max x_{i} \\
0 x_{i}>\max x_{i}
\end{array}\right.
$$

where Uij ( $x i$ ) was the membership function from the $j$ shrub corresponding to the I evaluation index; $\max x_{i}$ and $\min x_{i}$ were respectively the upper limit and lower limit for each evaluation index in the comment set.

Refer to the evaluation set established previously to obtain the evaluation index set of physiological characteristics, landscape function, and the ecological service function for Ligustrum vicaryi under different soil cover mulch; the results are shown in Table 2. 
Table 2. The division of evaluation index and evaluation set.

\begin{tabular}{|c|c|c|c|c|c|}
\hline \multirow[b]{2}{*}{ Evaluation Set } & \multicolumn{5}{|c|}{ Evaluation Index } \\
\hline & $\begin{array}{l}\text { LA }\left(\mathrm{cm}^{2}\right) \\
\text { Leaf Area }\end{array}$ & $\begin{array}{c}\text { TLA }\left(\mathrm{cm}^{2}\right) \\
\text { Total Leaf Area }\end{array}$ & $\begin{array}{c}\text { LAI } \\
\text { Leaf Area Index }\end{array}$ & $\begin{array}{l}\text { Pn }\left(\mathrm{mmol} \cdot \mathrm{m}^{-2} \cdot \mathrm{d}^{-1}\right) \\
\text { Photosynthetic Rate }\end{array}$ & $\begin{array}{l}\operatorname{Tr}\left(\mathrm{mmol} \cdot \mathrm{m}^{-2} \cdot \mathrm{s}^{-1}\right) \\
\text { Transpiration Rate }\end{array}$ \\
\hline Optimal & $>11$ & $>1100$ & $>0.4$ & $>4$ & $>3$ \\
\hline Good & $10-11$ & $900-1000$ & $0.3-0.4$ & $3.5-4.0$ & $2.5-3.0$ \\
\hline Middle & $9-10$ & $800-900$ & $0.2-0.3$ & $3.0-3.5$ & $2.0-2.5$ \\
\hline Poor & $8-9$ & $700-800$ & $0.1-0.2$ & $2.5-3.0$ & $1.5-2.0$ \\
\hline \multirow[t]{2}{*}{ Bad } & $<8$ & $<700$ & $<0.1$ & $<2.5$ & $<1.5$ \\
\hline & $\begin{array}{c}\text { WUE } \\
\left(\mu \mathrm{molCO}_{2} / \mathrm{mmolH}_{2} \mathrm{O}\right) \\
\text { Water use efficiency }\end{array}$ & $\begin{array}{l}\text { Carbon fixation } \\
\left(\mathrm{g} \cdot \mathrm{m}^{-2} \cdot \mathrm{d}^{-1}\right)\end{array}$ & $\begin{array}{l}\text { Releasing oxygen } \\
\quad\left(\mathrm{g} \cdot \mathrm{m}^{-2} \cdot \mathrm{d}^{-1}\right)\end{array}$ & $\begin{array}{l}\text { humidification } \\
\left(\mathrm{g} \cdot \mathrm{m}^{-2} \cdot \mathrm{d}^{-1}\right)\end{array}$ & cooling $\mathrm{kJ} /\left(\mathrm{m}^{2} \cdot \mathrm{d}\right)$ \\
\hline Optimal & $>4$ & $>5$ & $>4$ & $>1700$ & $>4000$ \\
\hline Good & $3-4$ & $4-5$ & $3-4$ & $1500-1700$ & $3500-4000$ \\
\hline Middle & $2-3$ & $3-4$ & $2-3$ & $1300-1500$ & $3000-3500$ \\
\hline Poor & $1-2$ & $2-3$ & $1-2$ & $1100-1300$ & $2500-3000$ \\
\hline Bad & $<1$ & $<2$ & $<1$ & $<1100$ & $<2500$ \\
\hline
\end{tabular}

\section{Results and Analysis}

\subsection{Influence of the Different Soil Covered Mode on Physiological and Ecological Results}

In order to quantitatively describe the physiological and ecological effects from the different soil covered mode for the typical city greening shrub Ligustrum vicaryi, data from 2011 and 2012 was studied in terms of landscape function, physical characteristics, and ecological service function. By measuring landscape parameters (LA, TLA, LAI), physical characteristics (Pn, Tr, WUE), and ecological service function parameters (carbon fixation, oxygen release, humidification, cooling) at different times and leaf growing positions, the data was analyzed to determine the influence of the different soil covered mode on landscape function, physiological characteristics, and ecological service function of Ligustrum vicaryi. The analysis results provided were mean values from two years of data.

\subsubsection{The Influence of the Different Soil Covered Mode on Landscape Functions}

By analyzing the data from the different treatments in Table 3, the results show that the leaf area (LA), total leaf area (TLA), and leaf area index (LAI) of Ligustrum vicaryi for all three cover treatments, which stand for landscape function parameters, were better than no mulch. This illustrated that the implementation of the soil covered mode was beneficial to the growth of Ligustrum vicaryi, suppressed excessive consumption of soil moisture because of evaporation, and saved water that was absorbed by plant roots to supply plant growth. The $\mathrm{CH} 3$ treatment was most advantageous for the growth of Ligustrum vicaryi. LA, TLA, and LAI of treatment $\mathrm{CH} 3$ was $21.4 \%, 21.9 \%$, and $62.5 \%$, respectively, larger than for those of $\mathrm{CK}$ (the control, no soil cover). The second best was treatment $\mathrm{CH} 2$.

Table 3. Influence of Ligustrum vicaryi leaf area under different mulch treatments.

\begin{tabular}{|c|c|c|c|c|}
\hline $\begin{array}{ll}\text { Parameter } & \text { Treatment } \\
\end{array}$ & $\begin{array}{c}\text { CK } \\
\text { Control Check }\end{array}$ & $\mathrm{CH} 3$ & $\mathrm{CH} 2$ & CH1 \\
\hline $\mathrm{S}_{2}\left(\mathrm{~cm}^{2}\right)$ & $8.86 \pm 1.08 \mathrm{a}$ & $10.76 \pm 2.01 a$ & $9.75 \pm 1.54 a$ & $8.90 \pm 1.50 a$ \\
\hline $\mathrm{S}_{1}\left(\mathrm{~cm}^{2}\right)$ & $841.96 \pm 79.32 c$ & $1026.14 \pm 71.85 a$ & $951.84 \pm 73.64 b$ & $898.17 \pm 36.16 b c$ \\
\hline LAI & 0.24 & 0.39 & 0.34 & 0.29 \\
\hline
\end{tabular}

Data followed by different letters $(\mathrm{a}, \mathrm{b}, \mathrm{c})$ within same columns at same stage are significantly different at $P_{0.05}$ level; values are mean $\pm \mathrm{SE}$ of each treatment. 


\subsubsection{The Influence of the Different Soil Cover Model on Photosynthetic Characteristics}

The physiological characterization index parameters of Ligustrum vicaryi for the different treatments, which included photosynthetic rate (Pn), transpiration rate (Tr), stomatal conductance (Gs), and water use efficiency (WUE), were measured in August. Analysis of variance was done on the measurement data; the results are shown in Table 4. The photosynthetic rate, transpiration rate, and water use efficiency of all three soil cover treatments were better than no mulch. This illustrates that implementation of soil cover assisted the physiological needs of Ligustrum vicaryi by allowing the soil moisture to be more fully absorbed by the plant roots. The nutrients in the soil water transported to the various plant organs promoted plant metabolism. By comparing each treatment, the results showed that the photosynthetic rate, transpiration rate, and water use efficiency (WUE) of the treatment $\mathrm{CH} 3$ was the best; and that the second best was $\mathrm{CH} 2$ treatment. The photosynthetic rate, transpiration rate, and water use efficiency (WUE) with treatment $\mathrm{CH} 3$ was $27.5 \%$, 35.8\%, and 96.8\% larger, respectively, than those with CK (no cover).

Table 4. Influence of Ligustrum vicaryi photosynthetic characteristics under different mulch treatments.

\begin{tabular}{ccccc}
\hline Treatment & CK & CH3 & CH2 & CH1 \\
\hline Parameter & $3.07 \pm 1.69 \mathrm{~b}$ & $3.94 \pm 1.71 \mathrm{a}$ & $3.26 \pm 1.26 \mathrm{~b}$ & $3.24 \pm 1.21 \mathrm{~b}$ \\
\hline $\operatorname{Pn}\left(\mu \mathrm{mol} \cdot \mathrm{m}^{-2} \cdot \mathrm{s}^{-1}\right)$ & $2.01 \pm 0.77 \mathrm{c}$ & $2.73 \pm 0.99 \mathrm{a}$ & $2.30 \pm 0.65 \mathrm{~b}$ & $2.36 \pm 0.92 \mathrm{~b}$ \\
\hline $\operatorname{Tr}\left(\mathrm{mmol} \cdot \mathrm{m}^{-2} \cdot \mathrm{s}^{-1}\right)$ & $1.75 \pm 1.73 \mathrm{~b}$ & $3.44 \pm 0.72 \mathrm{a}$ & $1.94 \pm 0.69 \mathrm{~b}$ & $1.69 \pm 0.95 \mathrm{~b}$ \\
\hline $\mathrm{WUE}$ & & &
\end{tabular}

Data followed by different letters $(\mathrm{a}, \mathrm{b}, \mathrm{c})$ within same columns at same stage are significantly different at $P_{0.05}$ level; values are mean $\pm \mathrm{SE}$ of each treatment.

It was necessary to study the change of photosynthetic rate, transpiration rate, and stomatal conductance of the main stem leaves and branch leaves of Ligustrum vicaryi quantitatively under the different soil cover treatments. During the experiment, photosynthetic rate, transpiration rate, and stomatal conductance of different azimuth leaves were measured at different times. The experiment results showed that (Figure 1) the photosynthetic rate of the four treatments was maximum in the morning, there was a "noon break" phenomenon apparent in the photosynthetic rate of CK and CH2 (in the middle of the day). The transpiration rate showed a trend of "single-peak" curve changes for each treatment, and reached the maximum at noon. The stomatal conductance for $\mathrm{CH} 2$ and $\mathrm{CH} 3$ were at maximum in the morning. 


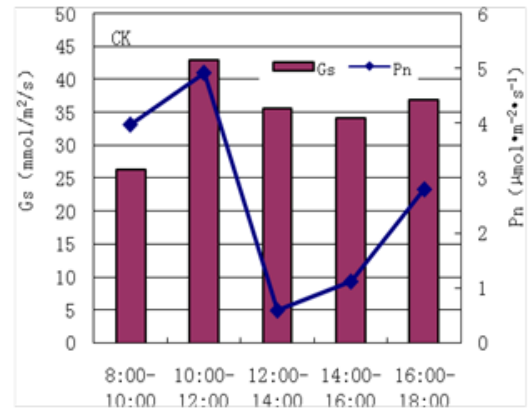

(a)

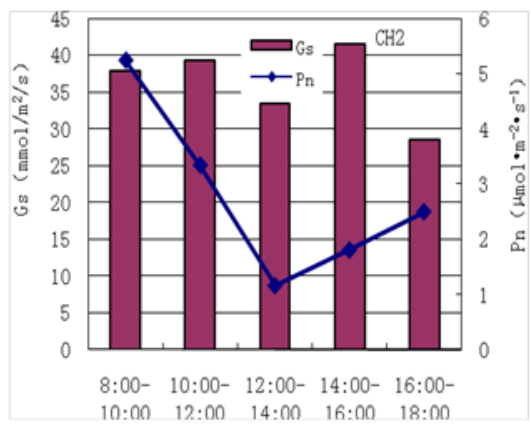

(c)

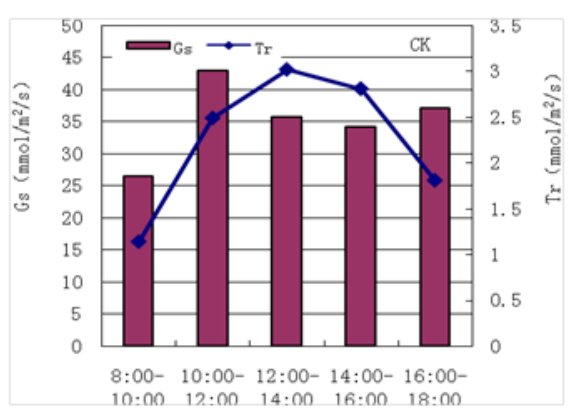

(e)

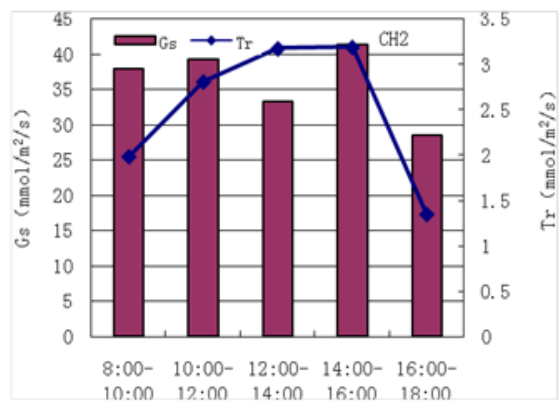

(g)

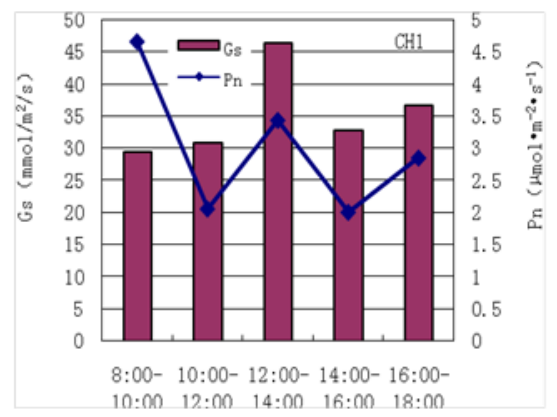

(b)

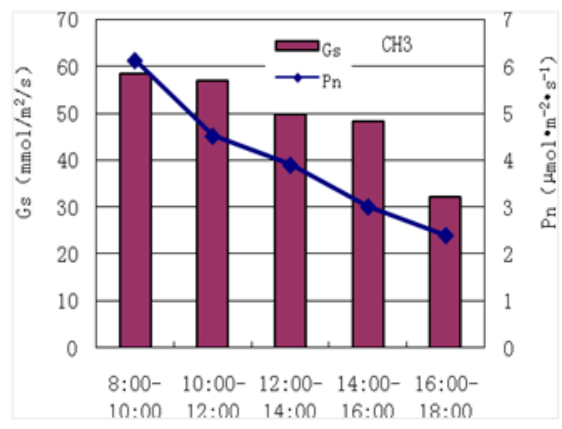

(d)

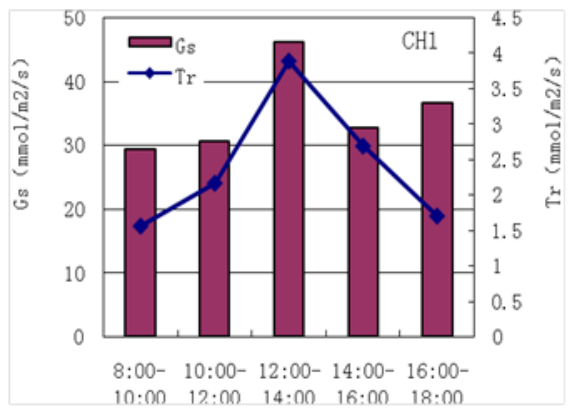

(f)

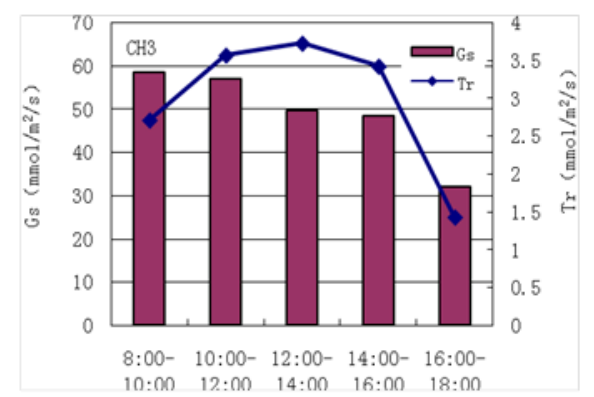

(h)

Figure 1. The influence of different soil cover treatments on Ligustrum vicaryi photosynthetic characteristics (a-d descript the Gs-stomatal conductance and Pn-photosynthetic rate in different treatments, and $\mathbf{e}-\mathbf{h}$ Gs and Tr- transpiration rate). 


\subsubsection{The Influence of the Different Soil Cover Model on Ecological Effect}

From the aspect of ecological service function (Table 5), the ecological effects of the three soil cover treatments were better than no mulch, and treatment $\mathrm{CH} 3$ was optimal. Compared with $\mathrm{CK}$, carbon fixation, oxygen release, cooling, and amount of humidification increased 34.3\%, 34.0\%, 46.1\%, and $34.3 \%$, respectively. The second best was $\mathrm{CH} 2$.

Table 5. Influence of different soil cover treatments on ecological effects for Ligustrum vicaryi.

\begin{tabular}{ccccc}
\hline Treatment & CK & CH3 & CH2 & CH1 \\
\hline $\begin{array}{c}\text { Carbon Fixation } \\
\left(\mathrm{g} \cdot \mathrm{m}^{-2} \cdot \mathrm{d}^{-1}\right)\end{array}$ & $3.64 \pm 0.46 \mathrm{~b}$ & $4.89 \pm 0.63 \mathrm{a}$ & $3.97 \pm 0.68 \mathrm{~b}$ & $3.90 \pm 0.65 \mathrm{~b}$ \\
\hline $\begin{array}{c}\text { Releasing oxygen } \\
\left(\mathrm{g} \cdot \mathrm{m}^{-2} \cdot \mathrm{d}^{-1}\right)\end{array}$ & $2.65 \pm 0.33 \mathrm{~b}$ & $3.5 \pm 0.46 \mathrm{a}$ & $2.89 \pm 0.49 \mathrm{~b}$ & $2.84 \pm 0.47 \mathrm{~b}$ \\
\hline $\begin{array}{c}\mathrm{Humidification} \\
\left(\mathrm{g} \cdot \mathrm{m}^{-2} \cdot \mathrm{d}^{-1}\right)\end{array}$ & $1108.8 \pm 129.6 \mathrm{c}$ & $1619.9 \pm 173.5 \mathrm{a}$ & $1376.0 \pm 101.1 \mathrm{~b}$ & $1320.8 \pm 89.5 \mathrm{~b}$ \\
\hline $\begin{array}{c}\mathrm{cooling} \\
\mathrm{kJ} /\left(\mathrm{m}^{2} \cdot \mathrm{d}\right)\end{array}$ & $2657.9 \pm 310.6 \mathrm{c}$ & $3883.1 \pm 415.8 \mathrm{a}$ & $3158.7 \pm 242.4 \mathrm{~b}$ & $3144.9 \pm 210.6 \mathrm{~b}$ \\
\hline
\end{tabular}

Data followed by different letters $(\mathrm{a}, \mathrm{b}, \mathrm{c})$ within same columns at same stage are significantly different at $P_{0.05}$ level; values are mean $\pm \mathrm{SE}$ of each treatment.

\subsection{Evaluation Based on the Fuzzy Mathematical Model}

\subsubsection{Weight Calculated}

Judgment matrix A was established based on the ten indicator parameters of growth and physiological characteristics parameters, landscape function, and ecological service function under different soil cover treatments, as follows:

$$
A=\left(\begin{array}{llllllllll}
1 & 1 & 1 & 3 & 2 & 3 & 5 & 5 & 3 & 3 \\
1 & 1 & 1 & 2 & 1 & 3 & 7 & 7 & 5 & 5 \\
\frac{1}{3} & \frac{1}{2} & 1 & 1 & 5 & 3 & 2 & 2 & 3 & 3 \\
\frac{1}{2} & 1 & \frac{1}{5} & 1 & 1 & 2 & 1 & 1 & 3 & 3 \\
\frac{1}{3} & \frac{1}{3} & \frac{1}{3} & \frac{1}{2} & 1 & 1 & 2 & 2 & 1 & 1 \\
\frac{1}{5} & \frac{1}{7} & \frac{1}{2} & 1 & \frac{1}{2} & 1 & 1 & 2 & 1 & 1 \\
\frac{1}{5} & \frac{1}{7} & \frac{1}{2} & 1 & \frac{1}{2} & \frac{1}{2} & 1 & 1 & 1 & 1 \\
\frac{1}{3} & \frac{1}{5} & \frac{1}{3} & \frac{1}{3} & 1 & 1 & 1 & 1 & 1 & 1 \\
\frac{1}{3} & \frac{1}{5} & \frac{1}{3} & \frac{1}{3} & 1 & 1 & 1 & 1 & 1 & 1
\end{array}\right)
$$

It was concluded, using Matlab statistical software, that the maximum characteristic value of matrix A: $\lambda_{\mathrm{Amax}}=11.07$. By calculation, C.R. $=0.079<0.1$, which suggests that matrix A passed the consistency check, which corresponded to eigenvectors $W=(0.53,0.57,0.25,0.40,0.27,0.17,0.15,0.13$, $0.14,0.13)$, and is acceptable as the weight of the evaluation index.

\subsubsection{Establishment of the Membership Function}

The membership function of each evaluation index was calculated as follows:

$$
U_{1 j}(x)=\left\{\begin{array}{ccc}
0 & x \leq 8 \\
\frac{1}{3} x-\frac{8}{3} & 8 \leq x \leq 11 \\
1 & x \geq 11
\end{array} \quad U_{2 j}(x)=\left\{\begin{array}{cc}
0 & x \leq 700 \\
\frac{1}{400} x-\frac{7}{4} \frac{1}{400} x-\frac{7}{4} & 700 \leq x \leq 1100 \\
1 & x \geq 1100
\end{array}\right.\right.
$$




$$
\begin{aligned}
& U_{3 j}(x)=\left\{\begin{array}{cc}
0 & x \leq 0.1 \\
\frac{10}{3} x-\frac{1}{3} & 0.1 \leq x \leq 0.4 \\
1 & x \geq 0.4
\end{array} \quad U_{4 j}(x)=\left\{\begin{array}{cc}
0 & x \leq 2.5 \\
\frac{2}{3} x-\frac{5}{3} & 2.5 \leq x \leq 4 \\
1 & x \geq 4
\end{array}\right.\right. \\
& U_{5 j}(x)=\left\{\begin{array}{cc}
1 & x \leq 1.5 \\
\frac{2}{3} x-1 & 1.5 \leq x \leq 3 \\
0 & x \geq 3
\end{array} \quad U_{6 j}(x)=\left\{\begin{array}{cc}
0 & x \leq 1 \\
\frac{1}{3} x-\frac{1}{3} & 1 \leq x \leq 4 \\
1 & x \geq 4
\end{array}\right.\right. \\
& U_{7 j}(x)=\left\{\begin{array}{ccc}
0 & x \leq 2 \\
\frac{1}{3} x-\frac{2}{3} & 2 \leq x \leq 5 \\
1 & x \geq 5
\end{array} \quad U_{8 j}(x)=\left\{\begin{array}{cc}
0 & x \leq 1 \\
\frac{1}{3} x-\frac{1}{3} & 1 \leq x \leq 4 \\
1 & x \geq 4
\end{array}\right.\right. \\
& U_{9 j}(x)=\left\{\begin{array}{ccc}
0 & x & \leq 1100 \\
\frac{1}{600} x-\frac{11}{6} & 1100 & \leq x \leq 1700 \\
1 & x & \geq 1700
\end{array} \quad U_{10 j}(x)=\left\{\begin{array}{cc}
0 & x \leq 2500 \\
\frac{1}{1500} x-\frac{5}{3} & 2500 \leq x \leq 4000 \\
1 & x \geq 4000
\end{array}\right.\right.
\end{aligned}
$$

\subsubsection{Evaluation Results}

After carrying out the fuzzy calculation by Uij (xi) calculated in the Part 3.2.2., we get the fuzzy relationship matrix:

$$
\mathrm{R}=\left(\begin{array}{llllllllll}
0.29 & 0.11 & 0.47 & 0.38 & 0.34 & 0.25 & 0.55 & 0.55 & 0.02 & 0.11 \\
0.92 & 0.57 & 0.97 & 0.96 & 0.82 & 0.81 & 0.96 & 1.30 & 1.73 & 0.92 \\
0.58 & 0.38 & 0.80 & 0.51 & 0.53 & 0.18 & 0.66 & 0.99 & 0.59 & 1.86 \\
0.30 & 0.25 & 0.63 & 0.49 & 0.57 & 0.23 & 0.63 & 0.61 & 0.73 & 0.43
\end{array}\right)
$$

The fuzzy comprehensive evaluation index set was calculated as follows:

$$
\mathrm{B}=\mathrm{W} \cdot \mathrm{R}=(\mathrm{bj}), \mathrm{j}=(1, \Lambda, \mathrm{m}), \mathrm{W}=(\mathrm{w} 1, \mathrm{w} 2, \Lambda, \mathrm{wn}), \sum_{i=1}^{n} w_{i}=1
$$

where $\mathrm{n}$ is the evaluation index number; $\mathrm{W}$ is the index of weight vector; and $\mathrm{bj}(\mathrm{j}=1,2, \mathrm{~m})$ is a fuzzy comprehensive evaluation index value. By calculation, $\mathrm{B}=(0.94,3.23,2.43,1.59)$. According to the classification standard of the evaluation target, evaluation set $\mathrm{E}$ was established as $=\{\mathrm{e} 1, \mathrm{e} 2, \Lambda$, etc. $\}, \mathrm{t}$ is the target level number (Table 6). From results of the comprehensive evaluation set $B$, the evaluation index of $\mathrm{CK}, \mathrm{CH} 1, \mathrm{CH} 2$, and $\mathrm{CH} 3$ was $0.94,3.23,2.43$, and 1.59, respectively. According to the evaluation set $\mathrm{E}$, the quality of Ligustrum vicaryi was bad, optimal, middle, and poor, respectively. It illustrated that the soil mulch mode had good benefits for the growth of green plants and the $\mathrm{CH} 3$ was the optimal mode for the typical city greening shrub Ligustrum vicaryi.

Table 6. Quality evaluation standard of Ligustrum vicaryi under different mulch treatments.

\begin{tabular}{ccc}
\hline Level & Comprehensive Evaluation Index & Quality Evaluation \\
\hline I & $3 \leq \mathrm{bj}$ (fuzzy comprehensive evaluation index value) & Optimal \\
II & $2.5 \leq \mathrm{bj} \leq 3$ & Good \\
III & $2 \leq \mathrm{bj} \leq 2.5$ & Middle \\
IV & $1.5 \leq \mathrm{bj} \leq 2$ & Poor \\
V & $\mathrm{bj} \leq 1.5$ & Bad \\
\hline
\end{tabular}

\section{Discussion}

By studying the growth and physiological characteristics of Ligustrum vicaryi, it was shown that the soil cover contributes to the growth of Ligustrum vicaryi. These results can be explained as the soil cover increasing the dielectric layer between the atmosphere and the soil, and, effectively, cutting off part of the solar radiation reaching the soil surface, which reduced the evaporation of the soil surface. 
At the same time, the soil surface cover reduces bare soil so that water is not immediately evaporated after irrigating. The additional infiltration of water into the soil enables the root system to absorb more soil moisture to use for growth.

The bark and gravel dual-element mulch model $(\mathrm{CH} 3)$ was optimal among the treatments tested. This conclusion can be explained in terms of the two function aspects: landscape function and ecological service function. In terms of landscape functions, this research indicated that leaf growth and leaf area of Ligustrum vicaryi is restrained when there is not soil cover, which reduced conservation of soil moisture and could lead to stress from low soil water. Hong Liyun reached similar conclusions after studying effects of different irrigation modes and bark cover on water eco-physiological characteristics of Gingko Biloba [19]. When the soil moisture evaporates more quickly into the air, it cannot fully be used for the growth of plants. Under such conditions, water required for growth of Ligustrum vicaryi exceeded what the plant was able to provide from the soil. Leaf growth appeared "dwarfed" when the soil moisture was controlled ( $75 \%-85 \%$ of $\mathrm{Fc}$ ). The bark and gravel dual-element mulch treatment was better than other treatments at conserving soil moisture, and would be preferable under conditions of water stress, to reduce soil moisture evaporation and; thus, make the soil moisture more fully available for in the growth of plants. Moreover, to aid their growth, Ligustrum vicaryi plants made adaptive adjustments to soil moisture through their own physiological regulation, and improved greatly their uptake of the nutrients needed for their growth. When leaf growth and leaf area are at their best, Ligustrum vicaryi is able to function fully in its urban greening landscape function as a typical shrub species. Regarding ecological effect, carbon fixation, oxygen release, humidification, and cooling of Ligustrum vicaryi were measurable in this research. These ecological effects were much better with the bark and gravel dual-element mulch treatment than with other treatments. This illustrates that Ligustrum vicaryi plants, through their own regulation, absorbed more nutrients from the soil, allocated more of them to the mechanism of photosynthesis, and better maintained their ability to absorb $\mathrm{CO}_{2}$.

By analyzing the data on the photosynthetic rates of leaves in different positions, this study showed that the stomatal conductance was maximum in the morning, with the two kinds of dual-element mulch treatments. This is explained as being due to physiological regulation by the plants. For all kinds of plants, physiological activities are relatively weak at night. After a night of "sleep", in order to replenish nutrients needed for the plant body, exchange with the outside is needed, and the exchange channel is the stomata. For this reason, the degree of the stomatal opening is greater in the morning. Chen et al. and Zhang et al. reached similar conclusions after studying stomatal conductance of peanuts and winter wheat $[20,21]$. The photosynthetic rate exhibited a downward trend all morning, which continued to form a trough in the middle of day. This phenomenon is explained by the fact that severe water deficiency causes a lower photosynthetic rate, which is a significant factor affecting porosity. This is because during serious water deficiency, leaves have a higher intercellular $\mathrm{CO}_{2}$ concentration, which impedes the respiratory system and results in a decline in plant physiological activity. This hinders the transport and distribution of photosynthetic products, and the photosynthetic rate decreases due to stomatal limitation. The solar radiation is stronger at noon, when the excitation energy captured by the leaves exceeds their capacity for carbon assimilation. The excess light energy is dissipative, causes low light energy utilization efficiency, and decreases the photosynthetic rate [22]. From another point of view, the photosynthetic rate increases with increasing temperature, within a certain temperature range. Temperature and photosynthetic rate are positively correlated, and key photosynthetic enzymes (e.g., Rubisco) have optimal activation temperatures between 25 and $30^{\circ} \mathrm{C}$. The enzyme activity directly affects the photosynthetic rate [23]. When the leaf temperature is too high, this will affect part of the related enzyme activity in the plant, which is not good for photosynthesis. Light and temperature affect the conditions that supply soil moisture, which plays an important role in controlling the leaf gas exchange [24]. This also explains why photosynthesis increases in the afternoon. The increase in leaf level WUE is likely due to improvement in the structure of the canopy microclimate, which leads to changes in the (leaf) blade boundary layer meteorological conditions. The same porosity condition that is effective for water loss makes possible better air 
exchange for greater accumulation of $\mathrm{CO}_{2}$ for photosynthesis. This may improve the relative humidity in the canopy, reduce leaf temperatures, improve the leaf water content, increase stomatal conductance, and reduce the stomatal factors limiting photosynthesis.

Through the analytic hierarchy process (AHP) and fuzzy mathematical model, the effects on landscape function, physical characteristics, and ecological service function of Ligustrum vicaryi of three soil cover treatments were evaluated. The optimal soil conservation mode suitable for the growth of Ligustrum vicaryi were explored. The evaluation results showed that implementation of all three soil cover treatments were better than no mulch. The bark and gravel dual-element mulch treatment was optimal, and the pine needle and gravel dual-element mulch treatment was second best.

\section{Conclusions}

(1) In this study, the growth and physiological aspects of the typical urban greening shrub species Ligustrum vicaryi were investigated in relation to three different soil cover treatments. The results showed that soil cover strengthened the metabolic mechanisms of the plants, allowed better absorption of nutrients from the soil to be used more fully in the plant metabolism, promoted the growth and physiological adjustment, and improved the overall metabolic function of the plants. Regarding the landscape function, comparing the different soil cover treatments showed improvement in the order: bark and gravel dual-element mulch > pine needle and gravel dual-element mulch > gravel mulch > no mulch. With bark and gravel dual-element mulch, the treatment leaf area, total leaf area, and leaf area index were, respectively, $21.4 \%, 21.9 \%$, and $62.5 \%$ greater than with no mulch. Regarding physiological characteristics, the photosynthetic rate, stomatal conductance, evaporation rate, and other physiological indicators were better with bark and gravel dual-element mulch treatment than with other treatments. Regarding ecological service functions, the bark and gravel dual-element mulch treatment was optimal for carbon fixation, oxygen release, cooling, and humidification.

(2) Using the analytic hierarchy process (AHP) and the fuzzy mathematical model for the evaluation of the effects of different soil cover treatments on the landscape function, ecological service function, and physiological characteristics of Ligustrum vicaryi was reliable and feasible. The model evaluation results match the actual ones. Considering the landscape function, the physical characteristics, and the comprehensive ecological service function, the preliminary thought is that bark and gravel dual-element mulch, with a layer thickness of $3 \mathrm{~cm}$, was the optimal soil cover treatment for the typical city greening shrub Ligustrum vicaryi.

Author Contributions: P.Y. S.R. and Y.L. conceived and designed the experiments; C.W. performed the experiments; Z.Y. and M.Z. analyzed the data; C.W. and P.Y. wrote the paper; and Y.W. and X.Z. reviewed the paper.

Funding: This research was funded by the National Water Pollution Control and Treatment Science and Technology Major Project (2017ZX07103-002).

Acknowledgments: We are grateful for the support from the China Agricultural University.

Conflicts of Interest: The authors declare no conflict of interest.

\section{References}

1. Hathwaya, E.A.; Sharplesb, S. The interaction of rivers and urbanform in mitigating the urban heat island effect: A UK case study. Build. Environ. 2012, 58, 14-22. [CrossRef]

2. Vailshery, L.S.; Jaganmohan, M.; Nagendra, H. Effect of street treeson microclimate and air pollution in a tropical city. Urban For. Urban Green. 2013, 12, 408-415. [CrossRef]

3. Yang, S.H. Primary study on effect of C-O balance of afforestatal trees in cities. Geogr. Res. 1994, 12, 74-79.

4. Qin, Z.; Li, Z.D.; Cheng, F.Y.; Chen, J.F.; Liang, B. Influence of canopy structural characteristics on cooling and humidifying effects of Populus tomentosa community on calm sunny summer days. Landsc. Urban Plan. 2014, 127, 75-82. [CrossRef] 
5. Cohen, P.; Potchter, O.; Matzarakis, A. Daily and seasonal climatic conditions of green urban open spaces in the Mediterranean climate and their impact on human comfort. Build. Environ. 2012, 51, 285-295. [CrossRef]

6. Yang, J.; McBride, J.; Zhou, J.X. The urban forest in Beijing and its role in air pollution reduction. Urban For. Urban Green. 2005, 3, 65-78. [CrossRef]

7. Jim, C.Y.; Chen, W.Y. Assessing the ecosystem service of air pollutant removal by urban trees in Guangzhou (China). J. Environ. Manag. 2007, 88, 665-673. [CrossRef]

8. Cai, T.Y.; Jia, Z.K.; Huang, Y.W.; Huang, H.J.; Meng, L.; Yang, B.P.; Li, H. Effect of different straw mulch rates on soil water conservation and water-saving benefits in spring maize field. Trans. CASE 2011, 27 (Suppl. 1), 238-243.

9. Yu, D. The application Research of Soil Improvement and Moisture Conservation Technology in Waste Sand and Gravel Pit Afforestation; Beijing Forestry University: Beijing, China, 2015.

10. Cook, H.; Valdes, G.; Lee, H. Mulch effects on rainfall interception, soil physical characteristics and temperature under Zea mays L. Soil Tillage Res. 2006, 91, 227-235. [CrossRef]

11. Li, X.; Wang, G.; Xue, X.; Xie, Y.; Chen, F.; Li, S. Evapotranspiration and water use efficiency of potted pakchoi under different surface coverage degrees. Trans. CASE 2009, 25, 54-58.

12. Wang, Y.J.; Xie, Z.K.; Malhi, S.S.; Xie, Z.; Malhi, S.S.; Vera, C.L.; Zhang, Y.B.; Wang, J.N. Effects of rainfall harvesting and mulching technologies on water use efficiency and crop yield in the semi-arid loess plateau, China. Agric. Water Manag. 2009, 96, 374-382. [CrossRef]

13. Ma, Y.; Li, X.; Yi, W.; Cui, B.; Li, Y. Effect of ridge and furrow rainwater harvesting system with gravel mulch on growth of sea buckthorn. Trans. CASE 2010, 26, 188-194.

14. Liu, Y.; Li, S.Q.; Chen, F.; Yang, S.J.; Chen, X.P. Soil water dynamics and water use efficiency in spring maize (Zea mays L.) fields subjected to different water management practices on the loess plateau, China. Agric. Water Manag. 2010, 97, 769-775. [CrossRef]

15. Chen, S.; Zhang, Q.; Guo, T.; Dai, X.; Wang, Y. Study on carbon fixation, oxygen release, humidity increase and temperature reduction of landscape trees in Changchun city. Hubei Agric. Sci. 2012, 4, 750-756.

16. Han, H.J. Study on the eco-physiological functions of main plant species in Harbin city. J. Jiangsu For. Sci. Technol. 2005, 32, 5-10.

17. Yang, S.H. A study on the effect of decreasing temperature and increasing humidity of urban afforestation trees. Geogr. Res. 1994, 12, 74-79.

18. Schoorl, J.M.; Veldkamp, A.; Bouma, J. The evaluation on suitability of land resource. Soil Sci. Soc. Am. J. 2002, 66, 1610-1620. [CrossRef]

19. Hong, L. Effects of Different Irrigation Modes and Bark Cover on Water Eco-Physiological Characteristics of Gingko Biloba; Central South University of Forestry and Technology: Changsha, China, 2008; p. 3940.

20. Chen, J.; Lv, G.; He, Y. Effects of soil water status on gas exchange of peanut and early rice leaves. Chin. J. Appl. Ecol. 2005, 16, 105-110.

21. Zhang, Y.Q.; Jiang, J. Effects of leaf water physiological ecology process of winter wheat on soil water stress condition. Arid Zone Res. 2001, 18, 57-61.

22. Muller, P.; Li, X.P.; Niyogit, K.K. Non-photochemical quenching A response to excess light energy. Plant Physiol. 2001, 125, 1558-1566. [CrossRef]

23. Salvucci, M.E.; Portis, A.R.; Ogren, W.L. Light and $\mathrm{CO}_{2}$ response of ribulose-1, 5-bisphosphate carboxylase/oxygenase activation in Arabidopsis leaves. Plant Physiol. 1986, 80, 655-659. [CrossRef] [PubMed]

24. Yang, C.; Yang, L. Plasticity of clonal modules of Leymus chinensis in response to different environment. Chin. J. Appl. Ecol. 1998, 9, 265-268.

(C) 2019 by the authors. Licensee MDPI, Basel, Switzerland. This article is an open access article distributed under the terms and conditions of the Creative Commons Attribution (CC BY) license (http:/ / creativecommons.org/licenses/by/4.0/). 